\title{
Anomalous Nucleolar and Chromosomal Organization in Induced Phenodeviants of Grasspea
}

\author{
Girjesh Kumar* and Ritambhara Tripathi \\ Plant Genetics Laboratory, Department of Botany, University of Allahabad, Allahabad-211002, India
}

Received August 1, 2007; accepted August 20, 2007

\begin{abstract}
Summary Three distinct variants differing for their phenotypic appearance and floral characters were identified and isolated in $\mathrm{M}_{1}$ generation of $200 \mathrm{~Gy}$ gamma irradiated set in Lathyrus sativus. They were subjected to meiotic analysis to understand their genotypic sensitivity to induced cytological changes. One interesting abnormality encountered during the present study was nucleolar dysfunctioning in the treated plants. Despite of chromosomal abnormalities like laggards, stickiness, micronuclei, etc. chiasma frequency was found to increase in the 3 plants isolated at 200 Gy dose of gamma rays. Pollen fertility was also moderately affected.
\end{abstract}

Key words Lathyrus sativus, Gamma rays, Nucleolar dysfunctioning, Chiasma frequency, Chromosomal abnormalities, Pollen fertility.

Induced mutations can be beneficially utilized for tailoring better varieties of crop plants by plant breeders. Many reports are available for successful use of mutation breeding in the production of new cultivars of many crops (Micke et al. 1985). Among several mutagens, the capacity of gamma rays to accelerate the frequency of teratological changes, which is fairly low in nature, has been utilized to induce various morphogenetic changes in plants. Mutation breeding employing gamma radiation was initiated to explore its potential for genetic up gradation as well as to elucidate the feasibility of developing translocation and multiple interchange stock, which has the tremendous value in linkage analysis (Micke et al. 1985).

Grasspea is a popular food and sometimes becomes the only available source of nutrition and survival for the poor section of population during drought and famine in Asian and African countries. Many crop improvement programmes are presently addressing researches on different aspects of grasspea (Handbury et al. 2000) and mutagenesis can be a valuable supplement to conventional breeding methods. Therefore, the present study was aimed to document and report some valuable informations on the cytological behaviour of grasspea and isolation of mutants induced by gamma irradiation.

\section{Materials and methods}

Healthy seeds of Lathyrus sativus var. Pusa-24 were procured from National Bureau of Plant and Genetic Resources (I.A.R.I.), New Delhi. Hundred seeds were irradiated at each dose of gamma rays $\left(\mathrm{Co}^{60}\right.$ source) viz. $200 \mathrm{~Gy}, 400 \mathrm{~Gy}, 600 \mathrm{~Gy}$ and $800 \mathrm{~Gy}$ at N.B.R.I, Lucknow, India. These seeds were sown in experimental pots to raise $\mathrm{M}_{1}$ generation along with their respective controls.

Young floral buds of these irradiated plants were fixed in $1: 3$ acetic acid: absolute alcohol solution for $24 \mathrm{~h}$ and then transferred in $70 \%$ alcohol. Anthers were squashed in $2 \%$ acetocarmine. Pollen fertility was estimated by using acetocarmine-glycerine stainability test.

\footnotetext{
* Corresponding author, e-mail: kumar_girjesh@yahoo.com
} 

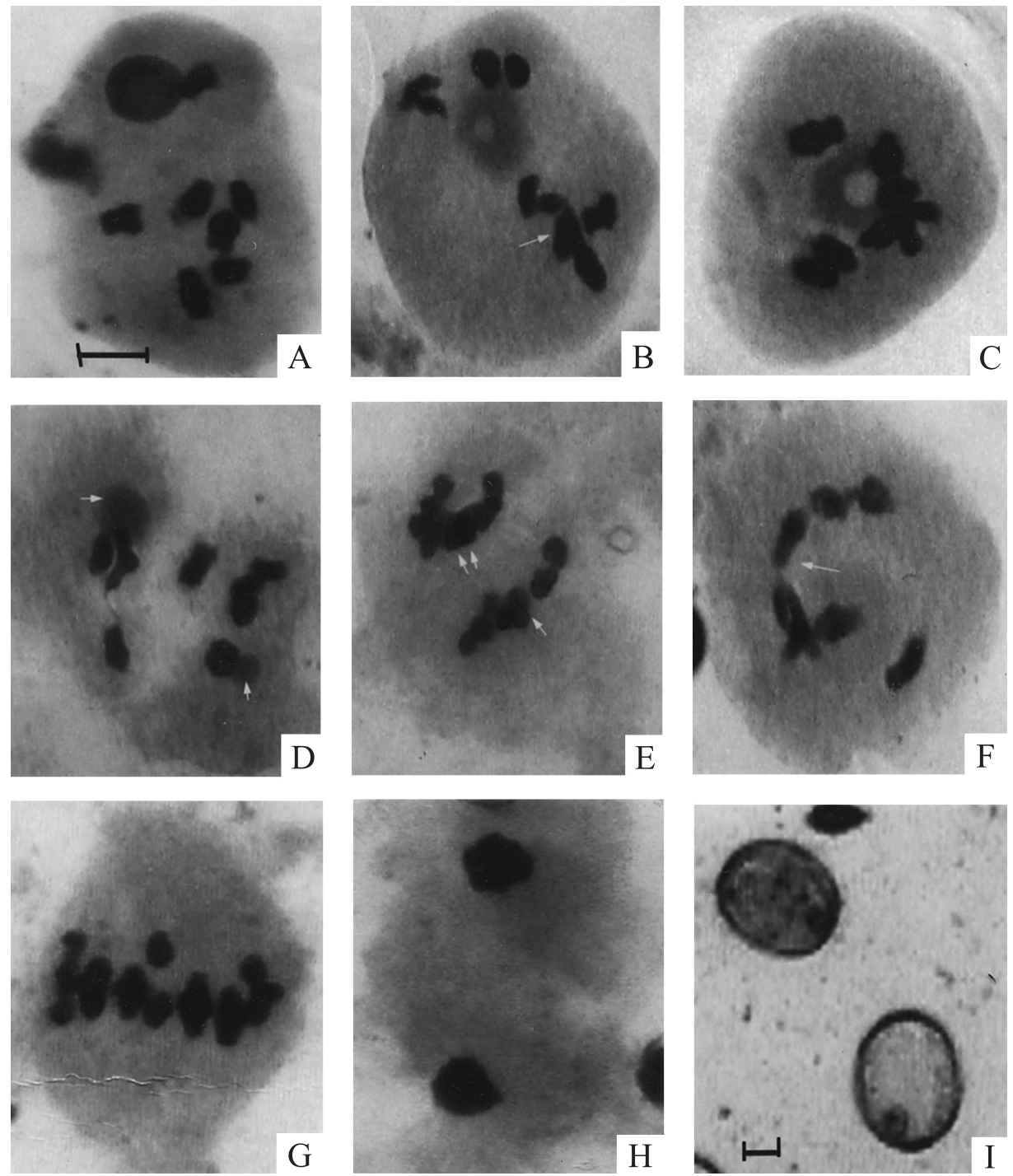

Fig. 1. A: Single bivalent attached to nucleolus in control $(n=7)$, B-D: Anomalous behaviour of bivalents at diplotene/diakinesis stages, B: Two bivalents attached to nucleolus, C: Many clumped bivalents attached to nucleolus, D: Nucleolar fragmentation (Two nucleoli shown by arrowheads), E-H: Chromosomal anomalies at metaphase and anaphase stages, E: Ring shaped multivalent (double arrowhead) and chain shaped quadrivalent (single arrowhead) at metaphase-I, F: Multivalent formation at metaphase-I, G: Precocious movement of chromosome at metaphase-I, H: Stickiness at anaphase-I, I: Fertile (darkly stained) and sterile (unstained) pollen grains at $10 \times$. (Fig. A-H, at $40 \times$, Fig. I at $10 \times$, Scale bar represents $10 \mu \mathrm{m})$.

\section{Observations}

During the analysis of irradiated sets of 4 different doses of gamma rays (200, 400, 600 and $800 \mathrm{~Gy}$ ), it was observed that in 200 Gy treated line, 3 plants out of 25 randomly selected plants displayed changed morphology. These morphologically distinct plants (Plant no. 1, 2 and 3) were isolated as variants and were found to be comparatively more vigorous than control and sib plants of the treated line of $200 \mathrm{~Gy}$ dose. Moreover, these plants were characterized by profuse branching, 
Table 1. Effect of Gamma Rays (200 Gy) on different morphological parameters in the three plants of Lathyrus sativus $\mathrm{L}$.

\begin{tabular}{lcccc}
\hline \hline & & & $200 \mathrm{~Gy}$ & \\
\cline { 3 - 4 } \multicolumn{1}{c}{ Plant characters } & Control & Plant No. 1 & Plant No. 2 & Plant No. 3 \\
\cline { 3 - 5 } & & 60.2 & 60.1 & 59.5 \\
Av. Plant height $(\mathrm{cm})$ & 58.6 & Maximum & Moderate $>$ Optimum & Low $>$ Optimum \\
Vigorosity & Optimum & $7.0 \times 2.0$ & $6.8 \times 2.0$ & $6.5 \times 1.7$ \\
Leaf size $(1 \times \mathrm{b} \mathrm{cm})$ & $6.0 \times 1.5$ & White & White & White \\
Flower colour & Purple & $82.4 \pm 0.12$ & $79.5 \pm 0.10$ & $75.6 \pm 0.13$ \\
Pollen fertility $(\%)$ & $98.2 \pm 0.14$ & & & \\
\hline
\end{tabular}

Table 2. Nucleolar Variations in three plants of 200 Gy set in Lathyrus sativus L.

\begin{tabular}{|c|c|c|c|c|c|c|c|}
\hline \multirow{2}{*}{ Plant No. } & \multirow{2}{*}{$\begin{array}{l}\text { Total No. } \\
\text { of PMCs } \\
\text { observed }\end{array}$} & \multicolumn{4}{|c|}{ No. of Bivalents attached to nucleolus } & \multirow{2}{*}{$\begin{array}{l}\text { Nucleolar } \\
\text { budding } \\
(\%)\end{array}$} & \multirow{2}{*}{$\begin{array}{c}\text { Persistent } \\
\text { nucleolus } \\
(\%)\end{array}$} \\
\hline & & SB & TB & MB & NB & & \\
\hline Control & 662 & 64.32 & - & - & - & - & - \\
\hline Plant No. 1 & 641 & 46.21 & 20.12 & 12.26 & 2.02 & 4.26 & 5.01 \\
\hline Plant No. 2 & 692 & 38.62 & 17.35 & 10.17 & 1.36 & 3.21 & 4.84 \\
\hline Plant No. 3 & 711 & 20.66 & 10.15 & 8.33 & 1.02 & 2.98 & 3.91 \\
\hline
\end{tabular}

Abbreviation: SB: Single bivalent, TB: Two bivalent, MB: Many bivalents, NB: No Bivalent.

Table 3. Meiotic Chromosomal associations, chiasma frequency/chromosome and various abnormalities in three plants of 200 Gy treated set

\begin{tabular}{|c|c|c|c|c|c|c|c|c|c|c|c|c|}
\hline \multirow{3}{*}{$\begin{array}{c}\text { Plant of } \\
\text { control/treated } \\
\text { set }\end{array}$} & \multirow{3}{*}{$\begin{array}{l}\text { Total no. } \\
\text { of PMCs } \\
\text { observed }\end{array}$} & \multicolumn{5}{|c|}{ Chromosomal associations } & \multirow{3}{*}{$\begin{array}{c}\text { Chiasma } \\
\mathrm{Fq} / \mathrm{Ch}\end{array}$} & \multicolumn{5}{|c|}{ Types of abnormalities (\%) } \\
\hline & & \multirow[t]{2}{*}{ Un. } & \multirow{2}{*}{$\begin{array}{l}\text { Bv. } \\
\text { Ring }\end{array}$} & \multicolumn{3}{|c|}{$\mathrm{Qv} / \mathrm{Mv}$} & & \multirow[t]{2}{*}{ PM } & \multirow[t]{2}{*}{$\mathrm{Lg}$} & \multirow[t]{2}{*}{$\mathrm{Bg}$} & \multirow[t]{2}{*}{$\mathrm{St}$} & \multirow[t]{2}{*}{$\mathrm{Mn}$} \\
\hline & & & & Rod & Ring & Chain & & & & & & \\
\hline Control & 251 & - & 7.5 & 3.2 & - & - & 0.63 & 0.11 & - & - & - & - \\
\hline Plant No. 1 & 256 & 0.23 & 8.6 & 4.4 & 4.2 & 2.5 & 0.74 & 1.23 & 2.46 & 2.01 & 2.42 & 1.32 \\
\hline Plant No. 2 & 280 & 0.18 & 8.3 & 4.0 & 3.6 & 1.8 & 0.71 & 1.19 & 2.32 & 2.00 & 2.22 & 1.28 \\
\hline Plant No. 3 & 248 & 0.15 & 7.8 & 3.7 & 3.2 & 1.3 & 0.65 & 1.01 & 2.43 & 1.86 & 2.43 & 1.26 \\
\hline
\end{tabular}

Abbreviations: Uv. Univalents, Bv. Bivalents, Qv. Quadrivalents, Mv. Multivalents, Fq. Frequency, Ch. Chromosome, PM. Precocious Movement, Lg. Laggard, Bg. Bridge, St. Stickiness, Mn. Micronuclei.

broader leaf area and white coloured flowers (Table 1).

Cytological studies were performed in order to determine the fact whether these phenotypic variations were associated with chromosomal structural changes or with point mutation. Cytological analysis of these plants clearly revealed a very interesting abnormality related to nucleolar behaviour at diplotene/diakinesis stage. A large number of PMCs showed varying degree of nucleolar anomalies like nucleolar budding/fragmentation, persistent nucleoli, micronuclei, etc.

Regarding the number of bivalents attached to the nucleolus, it was observed that in the pollen mother cells (PMCs) of control plants, only one bivalent was found attached (Fig. 1A) while in these 3 treated plants, the number of bivalents attached to nucleolus varied. Few of them showed 2 (Fig. 1B), 3 or many clumped bivalents (Fig. 1C) attached to nucleolus.

Out of 641, 692 and 711 PMCs studied in Plant no. 1, 2 and 3, respectively 152, 126 and 142 of them showed abnormal nucleolar behaviour (Table 2). The percentage of nucleolar budding with 
two (Fig. 1D) or more nucleoli was found comparatively lower than that of persistent nucleoli. At diakinesis, the situation was just reverse i.e. most of the PMCs had one nucleolus. Out of 135 PMCs observed, 125 showed one nucleolus and only 10 showed more than one nucleolus in the treated plants.

In case of treated plants, PMCs at diakinesis stage showed reciprocal translocations. Ring and chain configurations were the common types of translocations observed. However, the PMCs of Plant no. 1 showed higher percentage of quadrivalent formation followed by Plant no. 2 and 3. Among the interchanges, multivalent in the form of ring and chain types (Fig. 1E and 1F) occurred more or less equal in number and among bivalents, rings predominated over the rods. The mean frequencies of various chromosomal associations and chiasmata have been listed in Table 3. Terminal chiasmata formation was comparatively higher than the intercalary chiasmata in Plant no. 1 followed by Plant no. 2 and 3. Univalent formation was very low in case of each plant.

It was worthnoting that chiasma frequency was found to be increased in these 3 plants of 200 Gy dose line (0.65-0.74) as compared to control (0.63) (Table 3). The PMCs of these 3 phenodeviants also displayed various other types of abnormalities like precocious movement (Fig. 1G), laggards, bridges, stickiness at anaphase-I (Fig. 1H), etc. Micronuclei at tetrad stage were also predominantly present and were found to be highest in Plant no. 1 (1.32\%) followed by Plant no. 2 $(1.28 \%)$ and Plant no. 3 (1.26\%).

Pollen fertility seemed to be moderately affected being $82.4 \%, 79.5 \%$ and $75.6 \%$ in Plant no. 1,2 and 3, respectively as compared to control sets where it was recorded as $98.2 \%$ (Table 1). Fertile pollen grains were darkly stained whereas sterile ones were unstained (Fig. 1I).

\section{Discussion}

Induced mutagenesis has been now accepted as a significant tool to break through the limitations of variability and to create variability in a short period of time (Yaqoob and Rashid 2001), (Akgun and Tosun 2004). A wide range of chromosomal variations has been induced by gamma radiation (Ahmad 1993, Vizir et al. 1994, Gecheff 1996, Alvarez et al. 1997, Riera-Lizarazu et al. 2000) but the predominance of nucleolar dysfunctioning during the present study has made it more interesting.

Nucleolar anomalies such as multinucleolate cells and persistent nucleoli have also been observed by Reddi and Reddi (1985) in rice with different chemicals like methylmethane sulfonate (MMS), diethylmethyl sulfonate (DEMS), demethyl sulfonate (DMS) and diethyl sulfonate (dES). Haque (1983) also observed abnormal nucleolar behaviour in the natural population of Salvia. The causes of variations in number of nucleoli at prophase could not be well understood. However, it is well assumed that it involved the formation of more than one nucleolus by the activity of one or more than one pair of chromosomes. Such nucleolar variations have been observed in some other plants like Scilla sibirica (Rees 1958) and Allium cepa (VedBrat and Dhingra 1973).

In the present case, it can be attributed to the affect of gamma rays on the nucleolar behaviour or this variation might simply be a reflection of instability of nucleolar organizing chromosomes. The number of nucleoli decreased from diplotene to diakinesis suggesting that the extra nucleoli were eliminated later on. Shaikh and Godward (1972) suggested that nucleolar fragmentation induced by the mutagen might have occurred as a consequence of breaks in nucleolar organizing regions of the chromosomes. Similar findings were reported by Kumar and Dubey (1998).

Mutagen induced chromosomal abnormalities viz. quadrivalents and higher multivalent associations including rings and chains have reported earlier by Kumar et al. (1986), Meshram et al. (1992). The occurrence of multivalents indicate that probably the gamma rays produced many breaks in the chromosomes that might had lead to reciprocal translocations, resulting in multivalent formation. Such types of associations have also been reported in irradiated plants of rice (Radha 
Devi and Reddi 1997). Increased chiasma frequency after the treatment with gamma irradiation was also reported by Rees (1955) in rye.

Stickiness has been reported as a result of partial dissociation of nucleoproteins and alterations in the pattern of organization (Evans 1962). Occurrence of bridges during gamma ray treatments seems more a result of paracentric inversions (Swanson 1965). Laggards at anaphase can also be attributed to delay terminalization. Regarding the micronuclei formation, Koduru and Rao (1981) suggested that these might be the result of abnormal meiotic divisions like precocious movement, laggards, etc.

Despite of the occurrence of various nucleolar and chromosomal abnormalities after the treatment with gamma rays, several morphological and cytological variations induced at 200 Gy dose were significant. Morphological traits such as profuse branching, increased plant height, increased vigorosity and modified flower colour exhibited by the plants isolated are of immense agronomic and economic significance for the conventional plant breeders of Lathyrus sativus. Pollen fertility was also found to be moderately affected confirming negligible loss in seed set.

Thus, our results conclude that the dose of $200 \mathrm{~Gy}$ gamma rays can profitably be applied to maximize the induction of mutations that would be beneficial for the crop improvement programmes of grasspea.

\section{Acknowledgements}

The authors are thankful to H.O.D. of Botany Department for providing necessary facilities. Thanks are also due to N.B.P.G.R., New Delhi for supplying seeds and N.B.R.I., Lucknow for gamma radiation.

\section{References}

Ahmad, S. 1993. Meiotic Studies in two cultivars of Cicer arietinum L. after gamma irradiation. Cytologia 58: 61-65.

Akgun I, and Tosun, M. 2004. Agricultural and cytological characteristics of M1 perennial rye (Secale montanum Guss.) as effected by the application of different doses of gamma rays. Pakistan Journal of Biological Sciences 7: 827-833.

Alvarez, E., Alonsono-Blanco, C., Suarez, R. G., Ferreira, J. J., Roca, A. and Giraldez, R. 1997. A strategy for detecting chromosome specific rearrangements in rye. Genome 40: 451-457.

Evans, H. J. 1962. Chromosome aberrations induced by ionizing radiations. Int. Rev. Cytol. 13: 221-232.

Gecheff, K. I. 1996. Production and identification of new structural chromosome mutations in barley (Hordeum vulgare). Theor. Appl. Genet. 92: 777-781.

Handbury, C. D., White, C. L., Mullan, B. P. and Siddique, K. H. M. 2000. A review of potential of Lathyrus sativus L. and L. cicera L. grain for use as animal feed. Animal Feed Science and Technology 82: 1-27.

Haque, S. 1983. Chiasma frequency and nucleolar behaviour in four species of Salvia L. Cytologia 48: 259-266.

Koduru, P. K. R. and Rao, M. K. 1981. Cytogenetics of synaptic mutants in higher plants. Theor Appl Genet. 59: $197-214$.

Kumar, O., Aniel, Panda, Ramesh, C. and RajaRao, K. G. 1986. Chromosome orientation and sterility in Gamma Ray induced interchanges in chilli pepper (Capsicum annuum L.). Cytologia 51: 717-721.

Kumar, S. and Dubey, D. K. 1998. Effect of gamma rays, EMS, DES on meiosis in Lathyrus sativus. J. Cytol. Genet. 33: 139-147.

Meshram, L. D., Narkhede, M. N. and Deshmukh, N. Y. 1981. Spontaneous multiple translocations in Capsicum annuum L. Cytologia 46: 75-79.

Micke, A., Maluszynski, M. and Donini, B. 1985. Plant cultivars derived from mutation induction or the use of induced mutants in cross breeding. Mutation Breed. Rev. 3: 1-92.

Radha Devi, K. and Reddi, T. V. V. 1997. Cytogenetics of interchange heterozygotes in scented rice by recurrent treatments with gamma rays. J. Cytol. Genet. 32: 129-133.

Reddi, V. R. and Reddi, T. V. V. S. 1975. A case of induced double interchange in rice involving six chromosomes. Mutation Res. 33: 421-424.

Rees, H. 1955a. Genotypic control of chromosome behaviour in rye 1. Inbred lines. Heredity 9: 93-116.

- 1958. Differential behaviour of chromosomes in Scilla. Chromosoma 9: 185.

Riera-Lizarazu, O., Vales, M. I., Ananiev, E. V., Rines, H. W. and Phillips, R. L. 2000. Production and characterization of 
maize chromosome 9 radiation hybrids derived from an oat-maize addition line. Genetics 156: 327-339.

Shaikh, M. A. and Godward, M. B. E. 1972. The meiotic consequences of radiation induced chromosome breajs in Lathyrus sativus and Vicia ervilla. Cytologia 37: 497-505.

Swanson, C. P. 1965. Cytology and cytogenetics. Prentice Hall Inc. USA.

Ved Brat, S. and Dhingra, B. 1973. Genetic systems in Allium V. Breakdown of classical system in Allium cepa. Nucleus 16: 11-19.

Vizir, I. Y., Anderson, M. L., Wilson, Z. A. and Mulligan, B. J. 1994. Isolation of deficiencies in the Arabidopsis genome by g-irradiation of pollen. Genetics 137: 1111-1119.

Yaqoob, M. and Rashid, A. 2001. Induced mutation studies in some mungbean (Vigna radiata L.) wilczek cultivars. Online Journal of Biological Sciences 1: 805-808. 